\title{
Assimilação foliar de enxofre elementar pela soja
}

\author{
Godofredo Cesar Vitti( ${ }^{(1)}$, José Laércio Favarin(2), Luiz Antonio Gallo(3), Sônia Maria de Stefano Piedade ${ }^{(4)}$, \\ Maria Regina Meirelles de Faria ${ }^{(1)}$ e Fernanda Cicarone ${ }^{(1)}$
}

\begin{abstract}
(1)Escola Superior de Agricultura Luiz de Queiroz (Esalq), Dep. de Solos e Nutrição de Plantas, Av. Pádua Dias, no 11, Caixa Postal 9 , CEP 13418-900 Piracicaba, SP. E-mail: gcvitti@esalq.usp.br, reginamf@hotmail.com, fernandacicarone@hotmail.com (2)Esalq, Dep. de Produção Vegetal. E-mail: jlfavari@esalq.usp.br ${ }^{(3)}$ Esalq, Dep. de Ciências Biológicas. E-mail: luagallo@esalq.usp.br (4)Esalq, Dep. de Ciências Exatas. E-mail: soniamsp@esalq.usp.br
\end{abstract}

Resumo - O objetivo deste trabalho foi avaliar a assimilação de enxofre elementar $\left(\mathrm{S}^{0}\right)$, aplicado nas folhas de soja, e sua eficiência comparada à adubação feita ao solo, de acordo com a dose e a natureza da fonte do nutriente. $\mathrm{O} \mathrm{S}^{0}$ aplicado às folhas, independentemente da dose e fonte, foi assimilado pela planta, o que acarretou em aumento no teor de proteína total na folha. Todas as fontes de $\mathrm{S}$ aplicadas às folhas aumentaram a produção de grãos, semelhantemente à aplicação ao solo. Observou-se uma mesma produtividade com o uso de $20 \mathrm{~kg} \mathrm{ha}^{-1} \mathrm{de} \mathrm{S}^{0}$ no solo ou de $6 \mathrm{~kg} \mathrm{ha}^{-1}$ via foliar. A eficiência da aplicação de $\mathrm{S}$ via foliar, com base no conteúdo de proteína solúvel total, foi superior à da aplicação ao solo.

Termos para indexação: Glycine max, produção de soja, proteína, glutationa redutase, nutrição vegetal.

\section{Foliar elementary sulfur assimilation by soybean}

\begin{abstract}
The objective of this work was to evaluate the elementary sulfur $\left(\mathrm{S}^{0}\right)$ assimilation applied on soybean leaves, and its efficiency compared to the fertilization done in the soil, according to the dose and nature of the nutrient source. The $\mathrm{S}^{0}$ applied to leaves, independently of the dose and source, was assimilated by the plant, what resulted in increase of total protein content in the leaf. All S sources applied to leaves increased the grain yield, similarly to the application to the soil. The same productivity was observed with the use of $20 \mathrm{~kg} \mathrm{ha}^{-1}$ of $\mathrm{S}^{0}$ in the soil or $6 \mathrm{~kg} \mathrm{ha}^{-1}$ applied to leaves. The elementary S application efficiency on leaves, based on the content of total soluble protein, was superior to application efficiency on soil.
\end{abstract}

Index terms: Glycine max, soybean yield, protein, glutathione reductase, plant nutricion.

\section{Introdução}

A deficiência de $\mathrm{S}$ na agricultura ocorre em diversas regiões do Brasil, em razão da baixa fertilidade do solo (Malavolta, 1982), associada à pequena quantidade de matéria orgânica, do aumento da exportação de $\mathrm{S}$ pelos grãos, causados por produtividade elevada das variedades melhoradas, e da lixiviação de sulfato, acentuada pela aplicação de calcário e fósforo.

$\mathrm{O}$ enxofre elementar $\left(\mathrm{S}^{0}\right)$, quando aplicado ao solo, somente é absorvido pelas plantas depois de sua oxidação a sulfato por meio de reações catalisadas, principalmente, por microrganismos (Horowitz \& Meurer, 2006).

A análise química em folhas de trigo, após aplicação de ${ }^{35} S^{0}$ por Legris-Delaporte et al. (1987), indicou que houve a absorção e assimilação de enxofre elementar, que foi incorporado em compostos orgânicos como os aminoácidos (cisteína, cistina, metionina e glutationa forma reduzida) e proteínas. Por sua vez, o estudo sobre o metabolismo do enxofre elementar, em cloroplastos de trigo e espinafre, por Jolivet et al. (1995), evidenciou que há síntese de compostos que contêm $\mathrm{S}$ (tiossulfato, cisteína e glutationa), a partir da absorção e metabolização de ${ }^{35} \mathrm{~S}^{0}$.

Em estudo sobre tempo de absorção e de translocação de fósforo e enxofre, Boaretto et al. (1986) forneceram enxofre via foliar para o feijoeiro, na forma de sulfato de potássio, com o $\mathrm{S}$ marcado $\left({ }^{35} \mathrm{~S}\right)$, e observaram que a absorção de $50 \%$ de S ocorre após 16 horas, e a translocação se inicia somente depois de oito horas da aplicação.

Não existem publicações recentes sobre o assunto, e poucas informações foram produzidas sobre a absorção e a assimilação de enxofre elementar $\left(\mathrm{S}^{0}\right)$ em compostos orgânicos. Este conhecimento é fundamental à aplicação foliar desse nutriente, indicado para a fertilização suplementar com a finalidade de corrigir sua deficiência durante o ciclo da cultura. 
No mercado brasileiro são comercializadas várias fontes de $\mathrm{S}^{0}$, sem o embasamento científico suficiente para se justificar o uso crescente dessas formulações em adubação foliar (Vitti et al., 2006).

O objetivo deste trabalho foi avaliar a absorção e assimilação do $\mathrm{S}^{0}$, aplicado à folha, e a sua eficiência em relação à adubação feita no solo, em função da dose e da natureza da fonte desse nutriente, na cultura de soja.

\section{Material e Métodos}

O experimento foi realizado em casa de vegetação, de agosto a dezembro de 2005, utilizando-se Neossolo Quartzarênico distrófico, de textura arenosa $\left(840 \mathrm{~g} \mathrm{~kg}^{-1}\right.$ de areia total) (Tabela 1). $\mathrm{O}$ teor de $\mathrm{S}$ determinado no solo foi baixo (3 $\left.\mathrm{mg} \mathrm{dm}^{-3}\right)$ (Vitti, 1988).

$\mathrm{O}$ solo, depois de destorroado, secado à sombra e moído, foi peneirado para separação da fração menor que $2 \mathrm{~mm}$, a qual foi incubada durante 30 dias, com calcário dolomítico (30\% de $\mathrm{CaO}, 18 \%$ de $\mathrm{MgO}$ e $96 \%$ de PRNT) em dose equivalente, para elevar a saturação por bases a $70 \%$, em vasos de plástico de $5 \mathrm{~L}$ (Tabela 1).

As sementes de soja, variedade BRS 133, foram desinfetadas com água sanitária diluída à proporção de 1:10, por imersão durante $5 \mathrm{~min}$, e lavadas com água destilada. As sementes foram colocadas, durante $40 \mathrm{~min}$, em solução com Bradyrizobium japonicum em dose calculada para fornecer 1.200 .000 células por semente (Embrapa Soja, 2004), tendo-se completado o tratamento com a aplicação de Mo $\left(20 \mathrm{~g} \mathrm{~kg}^{-1}\right)$ e Co $\left(3,5 \mathrm{~g} \mathrm{~kg}^{-1}\right)$, em dose equivalente à quantidade de sementes necessária para o plantio de um hectare. A semeadura foi feita à profundidade de $2 \mathrm{~cm}$, tendo-se deixado, após a emergência, quatro plantas por recipiente.

O experimento foi constituído de sete tratamentos, dispostos em blocos ao acaso, tendo-se combinado métodos de aplicação de enxofre (foliar, solo e solo + foliar), doses do nutriente aplicado às folhas $\left(6 \mathrm{e} 8 \mathrm{~kg} \mathrm{ha}^{-1}\right) \mathrm{e}$ ao solo $\left(20 \mathrm{~kg} \mathrm{ha}^{-1}\right)$, e fontes de $\mathrm{S}$ elementar (pó molhável $90 \%$ de S; suspensão homogênea $-55 \%$ de S; e pó ventilado - 95\% de S), com quatro repetições (Tabela 2).
Para o plantio da soja, foram misturados, em $5 \mathrm{~L}$ de solo: $15 \mathrm{mg} \mathrm{kg}^{-1}$ de $\mathrm{N} ; 200 \mathrm{mg} \mathrm{kg}^{-1}$ de P; $150 \mathrm{mg} \mathrm{kg}^{-1}$ de $\mathrm{K} ; 75 \mathrm{mg} \mathrm{kg}^{-1} \mathrm{de} \mathrm{Ca} ; 15 \mathrm{mg} \mathrm{kg}^{-1} \mathrm{de} \mathrm{Mg} ; 0,5 \mathrm{mg} \mathrm{kg}^{-1}$ de B; $1,5 \mathrm{mg} \mathrm{kg}^{-1} \mathrm{de} \mathrm{Cu} ; 5 \mathrm{mg} \mathrm{kg}^{-1}$ de Fe; $3 \mathrm{mg} \mathrm{kg}^{-1}$ de Mn; $5 \mathrm{mg} \mathrm{kg}^{-1}$ de Zn e $0,1 \mathrm{mg} \mathrm{kg}^{-1}$ de Mo; de acordo com a recomendação padrão para ensaio em casa de vegetação, proposta por Malavolta (1980). As fontes dos nutrientes não continham enxofre em sua composição, para não influenciar as dosagens dos tratamentos.

A dose total de $\mathrm{N}\left(15 \mathrm{mg} \mathrm{kg}^{-1}\right)$ foi fornecida em duas vezes, a primeira misturada com o solo $\left(8 \mathrm{mg} \mathrm{kg}^{-1}\right) \mathrm{e} \mathrm{a}$ segunda em cobertura $\left(7 \mathrm{mg} \mathrm{kg}^{-1}\right)$. Quanto ao $\mathrm{K}$, $50 \mathrm{mg} \mathrm{kg}^{-1} \mathrm{de}_{2} \mathrm{O}$ foi misturado ao solo, e a dose restante foi aplicada em quatro coberturas de $25 \mathrm{mg} \mathrm{kg}^{-1}$, para evitar o risco de perdas por lixiviação e efeito salino.

As adubações foliares com $\mathrm{S}$ foram realizadas em duas épocas, a primeira no estádio V4, quando as plantas apresentavam quatro trifólios expandidos, e a segunda no estádio R1, com plantas no início do florescimento. Nas adubações foliares, os fertilizantes foram aplicados às plantas com um pulverizador de pressão manual de $1.000 \mathrm{~mL}$ e bico cônico. A superfície do solo foi protegida da deriva de $\mathrm{S}$ durante a aplicação foliar, por meio de uma cobertura com plástico, nos tratamentos T2, T4 e T7 e sem a proteção durante a pulverização das plantas dos tratamentos T3 e T5. Em cada conjunto de quatro plantas por vaso, foram aplicados às folhas $25 \mathrm{~mL}$ de uma solução contendo $\mathrm{S}^{0}$, de acordo com a dose definida para cada tratamento (Tabela 2). No cálculo do volume de calda por planta, foi considerada população de 400 mil plantas por hectare e pulverização com alto volume $\left(2.000 \mathrm{~L} \mathrm{ha}^{-1}\right)$, que equivale a $20 \mathrm{~mL}$ nas quatro plantas por vaso. Assim, com a aplicação de $25 \mathrm{~mL}$ por tratamento, obteve-se o molhamento adequado de toda a superfície foliar das quatro plantas de cada vaso.

Depois de 15 dias da segunda aplicação do fertilizante, coletou-se o $4^{\circ}$ trifólio, a partir da base de quatro plantas por repetição, para a determinação da atividade da glutationa redutase (GR) e da quantidade de proteína total solúvel ( $\mathrm{mg} \mathrm{g}^{-1}$ de MF) nas folhas da soja, confor-

Tabela 1. Resultados das análises químicas de solo, antes ${ }^{(1)}$ e depois da incubação $\left(\mathrm{T} 1\right.$ a T7) ${ }^{(2)}$ do solo com calcário dolomítico.

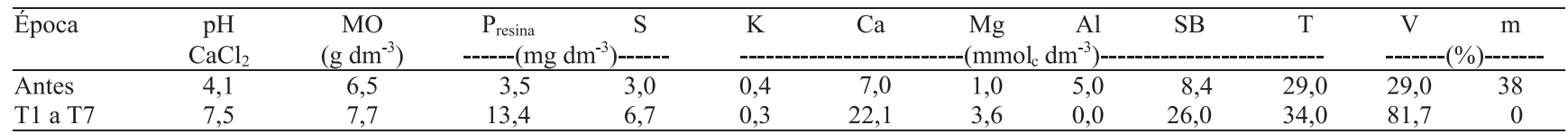

${ }^{(1)}$ Média de três repetições. ${ }^{(2)}$ Média de quatro repetições. 
me Bradford (1976). A atividade da GR foi determinada segundo Pompeu (2005) e monitorada pela redução da glutationa, acompanhada pela alteração da absorbância a $412 \mathrm{~nm}$, cujos resultados determinados foram expressos em micromoles de glutationa reduzida por minuto por miligrama de proteína.

Para a análise da quantidade de $\mathrm{S}$ foliar $\left(\mathrm{mg} \mathrm{planta}^{-1}\right)$, coletou-se o 5 o trifólio, a partir da base de três plantas por repetição, na mesma época (15 dias após a 2 $2^{\mathrm{a}}$ aplicação). O fertilizante presente na superfície das folhas foi eliminado por lavagem com água destilada, seguida da imersão em solução com detergente neutro e nova lavagem em água destilada. As folhas foram, então, imersas em solução de $\mathrm{HCl}$ (uma parte de $\mathrm{HCl}$ concentrado para nove partes de água) e, finalmente, uma última lavagem em água destilada. Esses cuidados foram adotados para que o $\mathrm{S}$ determinado na folha fosse, efetivamente, aquele absorvido pelas plantas. No cálculo da eficiência da aplicação foliar de $\mathrm{S}^{0}$, em relação ao fornecimento ao solo, considerou-se o teor de proteína total solúvel nas folhas ( $\mathrm{mg} \mathrm{g}^{-1} \mathrm{MF}$ ).

A avaliação do estado nutricional, em relação ao teor de $\mathrm{S}\left(\mathrm{mg} \mathrm{kg}^{-1}\right)$ contido na folha foi feita no $4^{\circ}$ trifólio, a partir do ápice de quatro plantas por repetição (Malavolta et al., 1997). No preparo da amostra repetiram-se os procedimentos descritos anteriormente, seguidos da secagem em estufa com circulação de ar a $70^{\circ} \mathrm{C}$, durante 48 horas. No final desse período, determinou-se a matéria seca das amostras e a quantidade de nutrientes, conforme Malavolta et al. (1997).

A produção $\left(\right.$ g planta $\left.^{-1}\right)$ de soja e o teor de $\mathrm{S}\left(\mathrm{mg} \mathrm{g}^{-1}\right)$ nos grãos foram obtidos em amostras colhidas em quatro plantas por parcela, nas quais se determinou o teor de água para a correção da umidade para $120 \mathrm{~g} \mathrm{~kg}^{-1}$,

Tabela 2. Doses de enxofre elementar $\left(\mathrm{kg} \mathrm{ha}^{-1}\right)$, natureza da fonte, épocas e formas de aplicação do nutriente.

\begin{tabular}{|c|c|c|}
\hline $\begin{array}{l}\text { Dose e natureza } \\
\text { da fonte de } S^{0}\end{array}$ & $\begin{array}{l}\text { Épocas de } \\
\text { aplicação }\end{array}$ & $\begin{array}{l}\text { Método de } \\
\text { aplicação }\end{array}$ \\
\hline T1. Controle & - & - \\
\hline $\begin{array}{l}\text { T2. } 8 \mathrm{~kg} \text { ha }{ }^{-1} \text { de } \mathrm{S} \text { (pó, formulação } \\
\text { molhável) }\end{array}$ & $\begin{array}{l}1 / 2 \text { estádio V4 + 1/2 } \\
\text { estádio R1 }\end{array}$ & Via foliar com proteção \\
\hline $\begin{array}{l}\text { T3. } 8 \mathrm{~kg} \text { ha-1 de S (pó, formulação } \\
\text { molhável) }\end{array}$ & $\begin{array}{l}1 / 2 \text { estádio V4 }+1 / 2 \\
\text { estádio R } 1\end{array}$ & Via foliar sem proteção \\
\hline $\begin{array}{l}\text { T4. } 6 \mathrm{~kg} \mathrm{ha}^{-1} \text { de S (fluído, suspensão } \\
\text { homogênea) }\end{array}$ & $\begin{array}{l}1 / 2 \text { estádio V4 + 1/2 } \\
\text { estádio R1 }\end{array}$ & Via foliar com proteção \\
\hline $\begin{array}{l}\text { T5. } 6 \mathrm{~kg} \mathrm{ha}^{-1} \text { de S (fluído, suspensão } \\
\text { homogênea) }\end{array}$ & $\begin{array}{l}1 / 2 \text { estádio V4 + 1/2 } \\
\text { estádio R } 1\end{array}$ & Via foliar sem proteção \\
\hline T6. $20 \mathrm{~kg} \mathrm{ha}^{-1}$ de S (pó, ventilado) & $\begin{array}{l}1 / 2 \text { semeadura }+1 / 2 \\
\text { cobertura }\end{array}$ & Via solo \\
\hline $\begin{array}{l}\text { T7. } 20 \mathrm{~kg} \mathrm{ha}^{-1} \text { de } \mathrm{S} \text { (pó, ventilado) e } \\
8 \mathrm{~kg} \mathrm{ha}^{-1} \mathrm{~S} \text { (pó, formulação } \\
\text { molhável) }\end{array}$ & $\begin{array}{l}1 / 2 \text { semeadura }+1 / 2 \\
\text { cobertura e } \\
1 / 2 \text { estádio V4 } 41 / 2 \\
\text { estádio } \mathrm{R} 1\end{array}$ & $\begin{array}{l}\text { Via solo e foliar com } \\
\text { proteção }\end{array}$ \\
\hline
\end{tabular}

para comparação da produtividade nas mesmas bases. Na sequiência, as amostras de grãos foram submetidas à análise para a determinação do teor de $\mathrm{S}$.

No final do experimento, após a colheita dos grãos, as folhas remanescentes, caules e raízes foram coletados separadamente, lavados para a eliminação de resíduos de solo e fertilizantes, e colocados para secar em estufa com circulação de ar a $70^{\circ} \mathrm{C}$, durante 48 horas. Ao final da secagem, obteve-se a massa de matéria seca de caules, folhas, raízes e da matéria seca total.

As médias de quantidades de $\mathrm{S}$ e $\mathrm{N}$ nas folhas, produção de grãos, teor de $\mathrm{S}$ nos grãos, atividade da GR, e quantidade de proteína total solúvel nas folhas de soja foram comparadas por meio de sete contrastes $(\mathrm{C} 1$ : T1 x T2, T3, T4, T5, T6 e T7; C2: T2, T3, T4 e T5 x T6 e T7; C3: T2 e T3 x T4 e T5; C4: T2 x T3; C5: T4 e T5; C6: T6 x T7; e C7: T2, T3, T4 e T5 x T6). No contraste 1, foram feitas comparações entre as plantas controle $\left(\mathrm{T} 1-\operatorname{sem} \mathrm{S}^{0}\right)$ e as plantas dos tratamentos que receberam o nutriente nas folhas (T2, T3, T4 e T5), no solo (T6) e solo + foliar (T7). Pelo contraste 2, compararam-se as médias obtidas nas plantas que receberam exclusivamente $S^{0}$ via foliar (T2, T3, T4 e T5) com as daquelas que receberam somente via solo (T6) e as médias das que foram adubadas tanto no solo quanto nas folhas (T7). No contraste 3, compararam-se as doses foliares de $S^{0}$ de $8 \mathrm{~kg} \mathrm{ha}^{-1}$ (T2 e T3) e $6 \mathrm{~kg} \mathrm{ha}^{-1}$ (T4 e T5), enquanto nos contrastes 4 e 5, dentro de cada dose foliar, compararam-se os resultados em solo protegido da aplicação foliar de $\mathrm{S}^{0}$. No contraste 6 , foram comparadas as médias obtidas com a aplicação de $S^{0}$ no solo e via foliar (T6) e a aplicação feita unicamente no solo (T7). Finalmente, pelo contraste 7, compararam-se os dados obtidos com a aplicação foliar, independentemente da dose (T2, T3, T4, e T5), com dados avaliados pelo fornecimento de $\mathrm{S}$ ao solo (T6).

As análises estatísticas foram feitas por meio de testes de comparações múltiplas das médias, em complemento ao teste $\mathrm{F}$, exceto para matéria seca total e o teor foliar de S, cujas médias foram comparadas pelo teste de Tukey a 5\% de probabilidade (Banzatto \& Kronka, 1995).

\section{Resultados e Discussão}

$\mathrm{O}$ fornecimento de $\mathrm{S}$ via foliar aumentou os teores de $\mathrm{S}$ e $\mathrm{N}$ nas folhas, independentemente da dose e da na- 
tureza química da fonte do nutriente (Tabela 3 ). $\mathrm{O}$ aumento no teor de $\mathrm{N}$ indica que a concentração desse nutriente na planta depende do fornecimento de $\mathrm{S}$ (Malavolta, 2006). O teor de S nas folhas não foi influenciado pela dose foliar, nem na presença nem na ausência da proteção do solo à aplicação, como comprovado pelo teor de $\mathrm{S}$, igual para ambas as doses, de 7,2 $\mathrm{mg}$ planta $^{-1}$ (Tabela 3).

A aplicação de $S^{0}$ foliar foi eficiente, pois elevou o teor foliar do nutriente (7,2 $\left.\mathrm{mg} \mathrm{planta}^{-1}\right)$, comparativamente à aplicação exclusiva ao solo $\left(4,9 \mathrm{mg}\right.$ planta $^{-1}$, Tabela 3). A aplicação combinada de $\mathrm{S}$ ao solo e às folhas (6,2 $\mathrm{mg}$ planta $\left.^{-1}\right)$ também propiciou maior teor foliar desse nutriente, quando comparada ao fornecimento exclusivo ao solo.

A produção de grãos foi influenciada pela adubação com S elementar, em conseqüência do baixo teor desse nutriente no solo, independentemente do método de aplicação (Tabela 3). A produção das plantas que receberam $S^{0}$ foliar não diferiu daquelas adubadas no solo. Esse resultado indica que houve absorção foliar de $S^{0}$, o que corrobora os resultados de Legris-Delaporte et al. (1987) e Jolivet et al. (1995), e indica que a adubação foliar com $S^{0}$ pode ser uma alternativa para o fornecimento de $S$ às plantas. As produções das plantas com o solo protegido da deriva de $\mathrm{S}$, durante a aplicação foliar, foram menores do que as das plantas com solo sem proteção, o que evidencia que este cuidado deve ser adotado para não incorrer em erros de interpretação (Tabela 3).

A quantidade de $S$ nos grãos não diferiu em razão dos tratamentos (Tabela 3), mesmo com o aumento no teor foliar pela aplicação do nutriente, o que pode ser explicado pela baixa translocação do nutriente na planta, também verificada na translocação das folhas velhas para as folhas novas (Epstein \& Bloom, 2006).

Os resultados da atividade da glutationa redutase (GR) e do teor de proteínas total solúvel, em consequiência da adubação foliar com $\mathrm{S}^{0}$, evidenciam grande variabilidade tanto no comportamento da enzima, quanto no teor de proteína total (Tabela 3). Este resultado está relacionado, provavelmente, com as múltiplas funções da glutationa, e com os vários fatores que influenciam a sua atividade (Taiz \& Zeiger, 2004). $\mathrm{O}$ fornecimento de $\mathrm{S}^{0}$ via foliar pode ter promovido a catalização da GR, pois houve aumento em sua atividade (3,0 $\mathrm{mmol} \mathrm{min}^{-1} \mathrm{mg}^{-1}$ proteína),em relação ao fornecimento do $\mathrm{S}^{0}$ ao solo (T6: $1,7 \mu \mathrm{mol} \mathrm{min}{ }^{-1} \mathrm{mg}^{-1}$ proteína), cuja absorção se dá na forma oxidada (Horowitz \& Meurer, 2006).

O conteúdo de proteína total solúvel nas folhas também aumentou com a aplicação foliar, em relação ao fornecimento ao solo. Portanto, houve assimilação de $\mathrm{S}$ nas folhas adubadas com $\mathrm{S}^{0}$, com incremento de 23,3 mg de proteína por grama de MF o que representa, aproximadamente, um ganho de $51 \%$ (Tabela 3 ). Esta observação corrobora os resultados obtidos por Legris-Delaporte et al. (1987), que constataram a assimilação de $S$ elementar $\left({ }^{35} \mathrm{~S}\right)$, que foi metabolizado em compostos orgânicos, como os aminoácidos cistina, metionina e glutationa. A quantidade de proteína total solúvel foliar, advinda da absorção exclusiva de $\mathrm{S}$ oxidado nativo do solo, foi inferior ao teor determinado nas plantas adubadas com S, embora a atividade da GR fosse semelhante (Tabela 3), uma indicação de que a formação de proteína sulfurada não é a única função desta enzima (Taiz \& Zeiger, 2004).

A matéria seca total aumentou com a aplicação de $S$, independentemente do método de aplicação de $\mathrm{S}$ e da natureza da fonte do nutriente (Tabela 4). Observou-se resultado semelhante para o teor foliar de $\mathrm{S}$ na folha diagnóstico, exceto para a aplicação ao solo, em que o teor foliar (S) não diferiu das plantas-controle (T1, Tabela 4). Ressalta-se que o teor de S na folha

Tabela 3. Comparações de médias de teor de enxofre e nitrogênio nas folhas ( $\left.\mathrm{mg} \mathrm{planta}^{-1}\right)$, produção de grãos $(\mathrm{g}$ planta-1 $)$, teor de enxofre nos grãos $\left(\mathrm{mg} \mathrm{g}^{-1}\right)$, atividade da glutationa redutase (GR) ( $\mu \mathrm{mol} \mathrm{min} \mathrm{mg}^{-1} \mathrm{mg}^{-1}$ proteína) e conteúdo de proteína total solúvel ( $\left.\mathrm{mg} \mathrm{g}^{-1} \mathrm{MF}\right)$ nas folhas de soja.

\begin{tabular}{|c|c|c|c|c|c|c|c|c|c|c|c|c|c|}
\hline Contraste & GL & $\mathrm{F}$ & $\begin{array}{l}\text { S na } \\
\text { folha }\end{array}$ & $\mathrm{F}$ & $\begin{array}{l}\mathrm{N} \text { na } \\
\text { folha }\end{array}$ & $\mathrm{F}$ & Produção & $\mathrm{F}$ & $\begin{array}{l}\mathrm{S} \text { dos } \\
\text { grãos }\end{array}$ & $\mathrm{F}$ & GR & $\mathrm{F}$ & $\begin{array}{l}\text { Proteína } \\
\text { na folha }\end{array}$ \\
\hline C1: T1 x T2 a T7 & 1 & $67,29 * *$ & $2,0 \times 6,9$ & $25,47^{* *}$ & $70,7 \times 162,4$ & $270,34 * *$ & $3,4 \times 6,5$ & $6,47^{\text {ns }}$ & $2,6 \times 1,8$ & $5,0^{\mathrm{ns}}$ & $3,3 \times 2,5$ & $10,76^{*}$ & $41,5 \times 65,7$ \\
\hline $\mathrm{C} 2: \mathrm{T} 2,3,4,5 \times \mathrm{T} 6,7$ & 1 & $4,62 *$ & $7,2 \times 6,2$ & $1,73^{\mathrm{ns}}$ & $168,8 \times 149,6$ & $13,62 * *$ & $6,3 \times 6,9$ & $1,02^{\text {ns }}$ & $1,8 \times 1,8$ & $29,67 * *$ & $3,0 \times 1,5$ & $2,29^{\text {ns }}$ & $62,7 \times 71,6$ \\
\hline $\mathrm{C} 3: \mathrm{T} 2,3 \times \mathrm{T} 4,5$ & 1 & $0,01^{\mathrm{ns}}$ & $7,2 \times 7,2$ & $1,57^{\mathrm{ns}}$ & $179,6 \times 158,2$ & $0,51^{\mathrm{ns}}$ & $6,2 \times 6,4$ & $0,01^{\mathrm{ns}}$ & $1,8 \times 1,8$ & $0,12^{\mathrm{ns}}$ & $2,9 \times 3,0$ & $1,13^{\text {ns }}$ & $66,3 \times 59,0$ \\
\hline $\mathrm{C} 4: \mathrm{T} 2 \times \mathrm{T} 3$ & 1 & $1,43^{\mathrm{ns}}$ & $6,8 \times 7,7$ & $0,01^{\mathrm{ns}}$ & $178,7 \times 179,9$ & $13,61 * *$ & $5,8 \times 6,7$ & $0,40^{\text {ns }}$ & $2,0 \times 1,6$ & $0,19^{\text {ns }}$ & $2,8 \times 3,0$ & $59,76 * *$ & $103,6 \times 29,0$ \\
\hline C5: T4 x T5 & 1 & $2,46^{\mathrm{ns}}$ & $6,6 \times 7,8$ & $1,09^{\mathrm{ns}}$ & $145,8 \times 170,6$ & $12,66 * *$ & $5,9 \times 6,8$ & $1,91^{\mathrm{ns}}$ & $1,7 \times 1,9$ & $91,91 * *$ & $5,2 \times 0,9$ & $52,80 * *$ & $24,0 \times 94,1$ \\
\hline C6: T6 x T7 & 1 & $10,13 * *$ & $4,9 \times 7,4$ & $0,03^{\text {ns }}$ & $151,7 \times 147,5$ & $4,43^{*}$ & $6,6 \times 7,1$ & $0,44^{\text {ns }}$ & $1,9 \times 1,6$ & $1,19^{\text {ns }}$ & $1,7 \times 1,3$ & $44,71 * *$ & $39,4 \times 103,9$ \\
\hline $\mathrm{C} 7: \mathrm{T} 2,3,4,5 \times \mathrm{T} 6$ & 1 & $13,54 * *$ & $7,2 \times 4,9$ & $0,83^{\text {ns }}$ & $168,8 \times 151,7$ & $2,33^{\text {ns }}$ & $6,3 \times 6,6$ & $1,44^{\mathrm{ns}}$ & $1,8 \times 1,9$ & $12,46 * *$ & $3,0 \times 1,7$ & $9,35^{*}$ & $62,7 \times 39,4$ \\
\hline Resíduo & 21 & - & - & - & - & - & - & - & - & - & - & - & - \\
\hline Total & 27 & - & - & - & - & - & - & - & - & - & - & - & - \\
\hline
\end{tabular}

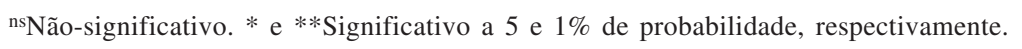


Tabela 4. Comparações múltiplas de médias de matéria seca total $\left(\mathrm{g}\right.$ planta $\left.{ }^{-1}\right)$ e teor de enxofre foliar $\left(\mathrm{g} \mathrm{kg}^{-1}\right)$ entre os trata$\operatorname{mentos}^{(1)}$.

\begin{tabular}{ccc}
\hline Tratamento & MS total & S foliar \\
\hline T1 & $14,33 \mathrm{~b}$ & $0,7 \mathrm{~b}$ \\
T2 & $22,56 \mathrm{a}$ & $1,3 \mathrm{a}$ \\
T3 & $24,87 \mathrm{a}$ & $1,3 \mathrm{a}$ \\
T4 & $22,20 \mathrm{a}$ & $1,3 \mathrm{a}$ \\
T5 & $24,16 \mathrm{a}$ & $1,4 \mathrm{a}$ \\
T6 & $23,95 \mathrm{a}$ & $0,9 \mathrm{~b}$ \\
T7 & $25,57 \mathrm{a}$ & $1,3 \mathrm{a}$ \\
\hline CV \% & 10,1 & 14,2 \\
DMS & 21,00 & 0,3 \\
\hline
\end{tabular}

${ }^{(1)}$ Médias seguidas por letras iguais não diferem entre si pelo teste de Tukey, a 5\% de probabilidade.

diagnóstico esteve abaixo dos valores considerados adequados pela faixa de interpretação $\left(2,1\right.$ a $\left.4 \mathrm{~g} \mathrm{~kg}^{-1}\right)$, em plantas de soja na condição de campo (Malavolta et al., 1997) (Tabela 4), em razão do baixo teor de matéria orgânica, de $\mathrm{S}$ nativo do solo, e em razão das baixas doses de $\mathrm{S}$ usadas neste trabalho. O fornecimento de $\mathrm{S}^{0}$ foliar praticamente dobrou o teor foliar de $\mathrm{S}$, que passou de $0,7 \mathrm{~g} \mathrm{~kg}^{-1}$ sem $\mathrm{S}$, para 1,3 a 1,4 $\mathrm{g} \mathrm{kg}^{-1}$ (Tabela 3), o que indica que a correção de deficiências pode ser conseguida pela aplicação suplementar às folhas.

\section{Conclusões}

1. O enxofre elementar aplicado às folhas é assimilado pela planta de soja, independentemente da dose e da natureza da fonte desse nutriente.

2. A aplicação foliar de enxofre elementar apresenta eficiência superior à aplicação feita ao solo.

\section{Agradecimentos}

Ao convênio Fealq/Intercuf Indústria e Comércio Ltda., pelo suporte técnico e financeiro.

\section{Referências}

BANZATTO, D.Z.; KRONKA, S.N. Experimentação agrícola. 3.ed. Jaboticabal: Funep, 1995. 247p.

BOARETTO, A.E.; MURAOKA, T.; CRUZ, A.P.; DAGHLIAN, C. Absorção de fósforo e enxofre pelas folhas do feijoeiro (Phaseolus vulgaris L.). Turrialba, v.36, p.120-123, 1986.
BRADFORD, M.M. A rapid and sensitive method for the quantitation of microgram quantities of protein utilizing the principle of protein-dye binding. Analytical Biochemistry, v.72, p.248-254, 1976.

EMBRAPA SOJA. Tecnologias de produção de soja: região Central do Brasil 2005. Londrina, 2004. 239p. (Embrapa Soja. Sistema de produção, 6).

EPSTEIN, E.; BLOOM, A.J. Nutrição mineral de plantas: princípios e perspectivas. 2.ed. Londrina: Planta, 2006. 403p.

HOROWITZ, N.; MEURER, E.J. Oxidação do enxofre elementar em solos tropicais. Ciência Rural, v.36, p.822-828, 2006.

JOLIVET, P.; BERGERON, E.; ZIMIERSKI, A.; MEUNIER, J.C. Metabolism of elemental sulphur and oxidation of sulphite by wheat and spinach chloroplasts. Phytochemistry, v.38, p.9-14, 1995.

LEGRIS-DELAPORTE, S.; FERRON, F.; LANDRY, J.; COSTES, C. Metabolization of elemental sulfur in wheat leaves consecutive to its foliar application. Plant Physiology, v.85, p.1026-1030, 1987.

MALAVOLTA, E. Elementos de nutrição mineral de plantas. São Paulo: Agronômica Ceres, 1980. 251p.

MALAVOLTA E. Manual de nutrição mineral de plantas. São Paulo: Agronômica Ceres, 2006. 638p.

MALAVOLTA, E. Nitrogênio e enxofre nos solos e culturas brasileiras. São Paulo: Centro de Pesquisa e Promoção do Sulfato de Amônio, 1982. 59p.

MALAVOLTA, E.; VITTI, G.C.; OLIVEIRA, S.A. Avaliação do estado nutricional das plantas: princípios e aplicações. 2.ed. Piracicaba: Potafos, 1997. 319p.

POMPEU, G.B. Análise da resposta antioxidativa de células in vitro de fumo (Nicotiana tabacum) submetidas ao metal pesado níquel. 2005. 97p. Dissertação (Mestrado) - Escola Superior de Agricultura Luiz de Queiroz, Piracicaba.

TAIZ, L.; ZEIGER, E. Fisiologia vegetal. 3.ed. Porto Alegre: Artmed, 2004. 719p.

VITTI, G.C. Avaliação e interpretação do enxofre no solo e na planta. Jaboticabal: Funep, 1988. 37p.

VITTI, G.C.; LIMA, E.; CICARONE, F. Cálcio, magnésio e enxofre. In: MANLIO, S.F. (Ed.). Nutrição mineral de plantas. Viçosa: Sociedade Brasileira de Ciência do Solo, 2006. p.299-325.

Recebido em 20 de julho de 2006 e aprovado em 24 de novembro de 2006 